\title{
Racial differences in pigmentation of the Fundus oculi'
}

An empirical evaluation of the correspondence between skin pigmentation and density of pigmentation in the Fundus oculi seemed desirable as a measure preliminary to further study of possible racial differences in perception. Fourteen Negro and 26 Caucasian males between the ages of $8-12$ (matched for age on an approximately one to two basis), were rated for density of fundus pigmentation on a four point scale by an opthalmologist. A close correspondence between race and fundus pigmentation density was found, with 12 of the 14 Negro children categorized in a distinctly denser class of fundus pigmentation than 24 of the 26 Caucasian children.

On finding differences between persons in European and non-European societies in perceptual phenomena, investigators have often concluded that the differences demonstrate the influence of "learning" on perception (e.g., Segall, Campbell, \& Herskovitz, 1963, 1966). In addition to the cultural differences, however, the comparison societies have been composed predominantly of individuals with darker skin pigmentation. If differences in skin color were associated with differences in retinal pigmentation, then this would provide some evidence that the obtained differences in some perceptual phenomena could be related to physiological parameters. Ishak (1952a, b), for example, found differences at the blue end of the spectrum in luminosity curves obtained for Egyptian and European Ss which he attributed to differences in the density of macular pigmentation between the respective groups. Pollack (1965) has suggested that an increased density of retinal pigmentation with age is a possible factor "serving to render the visual receptor system less sensitive to those variables which underlie configuration, figure-ground contrast, intercontour distance and contour orientation." The present study describes a preliminary evaluation of the differences in pigmentation of the Fundus oculi ${ }^{2}$ in American Negroes and Caucasians.

Subjects $^{3}$

Ss were 40 male children between the ages of 8 and 12. The 14 Negro and 26 Caucasian children were matched for age on an approximate one to two basis. Procedure

Gross ratings of pigmentation density of the fundus may be readily obtained using an opthalmoscope. For this study an opthalmologist ${ }^{4}$ using a Keeler opthalmoscope was asked to rate Ss for density of fundus pigmentation 5 on an appropriate scale. Examinations were begun with a basic two point "light" and "dark" distinction. As the number of Ss examined increased, several pronounced cases in both categories permitted
STEVEN D. SILVAR AND ROBERT H. POLLACK INSTITUTE FOR JUVENILE RESEARCH, CHICAGO

Table 1. Macular Pigmentation Ratings by Race.

\begin{tabular}{lcccc} 
& \multicolumn{2}{c}{ Light } & \multicolumn{2}{c}{ Dark } \\
& $1 / 1$ & $1 / 2$ & $2 / 1$ & $2 / 2$ \\
\hline Negro & 0 & 1 & 9 & 4 \\
Caucasian & 7 & 17 & 2 & 0 \\
\hline
\end{tabular}

the use of a four point scale. Rating $1 / 1$ describes the lightly pigmented often called "blond" fundus and $2 / 2$ a heavily pigmented slate gray appearing fundus, both still within the range of normality. The foveal region appears in each instance as a darker patch because of the macular pigmentation. The $1 / 2$ and $2 / 1$ ratings represent similar but slightly less pronounced "light" and "dark" distinctions.

Results

The opthalmologist's rating of the $40 \mathrm{Ss}$ on the four point scale is summarized in Table 1 . The $1 / 2$ and $2 / 1$ ratings obviously identify the bulk of the Caucasian and Negro sample, respectively. Differences between races on a consolidated two point scale of density of fundus pigmentation yielded a corrected chi-square of $42.39(p<.001)$. This examination supports the assumption that racial differences significantly predict discernible differences in density of pigmentation of the Fundus oculi. The possible consequences of this finding for perceptual behavior are to be investigated.

\section{References}

Ishak, I. G. H. The photopic luminosity curve for a group of fifteen Egyptian trichromats. J. Opt. Soc. Amer., 1952a, 42, 529-534.

Ishak, I. G. H. The spectral chromaticity coordinates for one British and eight Egyptian trichromats. J. Opt. Soc, Amer., 1952b, 42, 534-539.

Pollack, R. H. Intelligence and perceptual development in childhood. Paper read at APA Convention, Chicago, September, 1965.

Segall, M. H., Campbell, D. T., \& Herskovitz, M. J. Cultural differences in the perception of geometric illusions. Science, 1963, $139,769-771$.

Segall, M. H., Campbell, D. T., \& Herskovitz, M. J. The influence of culture on visual perception. Indianapolis, Indiana: The Bobbs-Merrill Company, 1966.

\section{Notes}

1. This research was supported by Grant No. HD 01433 awarded by the National Institute of Child Health and Human Development. 2. This includes the pigmentation of the choroidal and retinal pigmentation layers and the yellow pigmentation of the Macula lutea 3. We are grateful for the cooperation of Mr. Ivan A. Baker, Superintendent of Schools, and the principals of the Algonquin, Beacon Hill, Blackhawk Elementary and Junior High, Mohawk, Westwood Junior High and Wildwood Schools in Park Forest, Illinois.

4. We wish to acknowledge the careful work and generous amount of time given this study by Barbara Spiro, M. D., Diplomate, American Board of Opthalmology, Associate in Opthalmology, University of Illinois, Assistant Attending in Opthalmology, Presbyterian-St. Lukes Hospital, and in private practice in Chicago.

5. Viewed at the posterior pole in ordinary light. 